\title{
AN EXPERIMENTAL INVESTIGATION OF R12 AND R134A REFRIGERANTS IN A TWO - PHASE EJECTOR EXPANSION REFRIGERATION
}

\author{
K. SIMHADRI ${ }^{1,2}$, P. SRINIVASA RAO ${ }^{2 *} \&$ M K. PASWAN ${ }^{3}$ \\ ${ }^{I}$ Department of Mechanical Engineering, GMR Institute of Technology, Rajam, Andhra Pradesh, India, \\ ${ }^{2 *}$ Department of Mechanical Engineering, Centurion University of Technology and Management, Odisha, India \\ ${ }^{3}$ Department of Mechanical Engineering, NIT Jamshedpur, Jharkhand, India
}

\begin{abstract}
Refrigerators and Air conditioners play a key role in domestic as well as commercial purposes. These appliances that are used for the cooling purposes have become more of a necessity in today's world. Yet most of the world can't afford them due to their high power consumption, high initial cost, low performance etc. Investigation is under way worldwide on the performance of the refrigeration system while reducing its compressor work. The primary objective of this paper is to improve the performance of a refrigeration system by installing an ejector as valve for expansion thereby improving the COP. The refrigerants used during our experiments are R12 and R134a, which are most commonly used in today's refrigeration methods. It is observed that with the use of ejector as an expander, the system exhibited a COP improvement of $22.7 \%$ and $13.59 \%$ than that of conventional systems with the refrigerants $R 12$ and $R 134$ a respectively.

KEYWORDS: Ejector, Refrigeration, Coefficient of Performance (COP), Vapour Compression \& Two-Phase Ejector Expansion
\end{abstract}

Received: Jun 01, 2020; Accepted: Jun 20, 2020; Published: Jun 29, 2020; Paper Id.: IJMPERDJUN2020120

\section{INTRODUCTION}

Refrigeration forms the basic core of comfort in living. Refrigeration is one of the world's leading utilizations of electronic power. The word "refrigeration" applies to air conditioning for households, enterprises, manufacturing, and refrigeration, fridge, and heat pump operations. Since the $1980 \mathrm{~s}$, there has been pressure from the refrigeration industry to improve efficiency and reduce the emission of chlorofluorocarbon (CFC) compounds that pose a serious threat to the environment. Attempts to reduce CFC emissions have usually made refrigeration systems less effective by using alternative refrigerants.

The theoretical reduction in pressure is known as an isenthalpic phase in a refrigeration cycle where the enthalpy stays constant. However, because of energy loss during throttling, the isenthalpic cycle induces reduced the capacity of the evaporator to cool. An efficiency-enhancing solution has been suggested to recover this loss of energy that requires an ejector that can be used to produce isotropic conditions where the entropy occurs throttling cycle remains constant. Such a cycle for expanding the ejector is called the refrigeration cycle. To recover some of the work that would otherwise be lost within the expansion valve, an ejector is used.

Huashan Li et al.[1] used R1234yf as a refrigerant With a permanent-pressure ejector to examine the output Characteristics of refrigerated ejector-expansion process (EERC). Additionally, the EERC R1234yf and R134a performance was compared. The study showed that Performance Coefficient (COP) and Volumetric Refrigeration power (VCC) of the EERC peak R1234yf at 5.91 and 2590.76kj / m3 respectively, R1234yf EERC at 40c condensing 
temperature and 50c evaporation temperature. Generally better output compared to the standard cooling cycle, particularly when the condensation temperature is higher and the evaporation temperature is lower. Also, the COP and VCC improvements of the R1234yf EERC over the standard cooling cycle are greater than the ones of the R134a cycle.

Fang Liu et al.[2] conducted a detailed examination of Cooling and Heating simultaneously performance of an emission transcritical CO2 expansion system with a variable speed compressor and an adjustable ejector under different operating conditions. Experimental findings show that under severe operating conditions the total efficiency and COP of an ejector $\mathrm{CO} 2$ device exceed its limit diameter of the ejector throat is $2 \mathrm{~mm}$. When the frequency of the compressor falls from $60 \mathrm{~Hz}$ to $35 \mathrm{~Hz}$, The overall COP of the ejector cycle may increase by up to 71.4 percent while the total efficiency Can be reduced by 21.3 per cent Low outdoor temperatures benefit COPs while indoor air temperatures are high benefits from Refrigeration and heating. Empirical correlations between COP's are formed With internal geometries for the ejector, Compressor performance, and operating conditions for optimizing $\mathrm{CO} 2$ vapor compression systems.

Lixing Zheng et al.[3] present a complex transcritical CO2-Expansion process cooling which is a promising cycle (EERC) cooling device since it's environmentally friendly design and small losses of throttling. Using mass and energy consumption equations, the mathematical models are formulated for gas coolers, evaporators, and separators. Model the ejector is built focused on a actual properties of $\mathrm{CO} 2$ and the variable efficiencies of the ejector portion are considered, as they differ with operating conditions. Inside an algebraic set of equations, the compressor and expansive valve are modelled. The model developed observes the presented transient simulation of the system-changing Opening expansion valve and ejector area ratio, which helps to understand the EERC characteristics and guide the control system.

Gourav Patel et al.[4] state that one alternative is the Use of the ejector as an expansion instrument. New advancement 'Ejector' component into the The new refrigeration system has opened research era. The primary component that decides how the EERS operates effectively is that ejector. Therefore, the construction of ejector and the study of its physical operating parameters have attracted particular attention. In this article an extension of a continuous mixing pressure ejector is used tool to present the thermodynamic analysis of natural refrigerant ( $\mathrm{R} 170)$ dependent vapor compression refrigeration cycles. R 170 yields by using the ejector as an expansion tool a 24.12 per cent maximum COP improvement.

Kapil Dev Choudhary et al.[5] carried out a thermodynamic analysis an extension of the transcritical N2O ejector as a refrigeration process. A two-phase ejector is used as the expansion valve instead of a conventional expansion valve. The effect on Various inlet motive and evaporator temperatures of the cycle performance parameters, are COP, cooling effect, compressor operation and two ejector performance parameters are entrainment ratio and pressure recovery ratio were assessed.

Krzysztof Banasiak et al.[6] conduct experimental and computational investigation into the optimal configuration of the ejector for a heat pump with limited capacity R744. Specific ejector configurations were tested for the diffuser including different lengths, mixer diameters and different angels of divergence. The ejector geometry was optimized on the basis of a simplified, 1-D ejector model. The efficiency is based on both numerical simulation and experimental work of the ejector has been shown to be particularly dependent on the length and mixer diameter and also on the angle of divergence of the diffuser. The increase in the performance coefficient (COP) 8 per cent over a conventional expansion valve system

Christian Lucas et al.[7] have performed experimental comparison of an typical CO2 expansion cooling 
and ejector cooling cycle. High-pressure variability was achieved for various Pressures for evaporation and temperatures for exiting the gas cooler. In addition, at these conditions of the ejector efficiency, entrainment ratio and ejector pressure recovery were investigated. All examined cycles were carried out using the same test system, thus reducing the errors of comparison. Compared with the average $\mathrm{COP}$ of the expansion valve period, $\mathrm{COP}$ changes were achieved with up to 22 per cent ejector efficiencies over the ejector period of 17 per cent.

Stefan Elbel et al.[8] The study carried out by presents experimental results obtained using a refrigerant ejector from a transcritical R744 system. The findings were contrasted with those of a traditional expansion valve system. The cooling capacity and COP increased at the same time by up to 8 percent and 7 percent for the test conditions considered. Experiments were analyzed to quantitatively determine the effects of changes in base ejector dimensions such as motive nozzles and diffuser size on device performance.

Li Zhao et al.[9] used zeotropic mixtures a numerical analysis is carried out to determine the efficiency of the ejector-expansion refrigeration process (EERC). A model for two-phase ejectors for zeotropic mixtures with constantpressure is developed. This explores the consequences of both the composition of the fluid and its working conditions. The $\mathrm{R} 134 \mathrm{a} / \mathrm{R} 143 \mathrm{a}$ mixture is selected as the results of the work and simulation, showing that The COP period increases first and then decreases as MFT (the R134a mass fraction) increases in the condition investigated. With MFT of 0.9, the COP gets a maximum value of 4.18 and yields a minimum value of 3.66 with MFT of 0.5.The COP improvements reach a maximum value of 10.47 percent with a mixture of $0.9 / 0.1$. This improvement increases at high condensing or low evaporation temperatures. The study of the exergies indicates that the most energy destruction is contributed by the compressor and ejector, and the efficiency of Cycle exergy reaches a maximum value of 0.7 with MFT.

Rounak Sahni [10] Claims that EERC is a not so widely used refrigeration process. The use of this method is relatively understated. It increases the performance of the standard refrigeration cycle by about 16 percent over the basic cycle through using the otherwise wasted energy In the form of the expansion valve of losses from the expansion process. The EERC system possesses high potential prove to be a very effective refrigeration method if properly harnessed. This paper aims to highlight the true features of this system in the expectation that it can make its way out in today's commercial industry.

\section{EXPERIMENTATION}

\subsection{Basic Refrigeration Test Rig}

The refrigerator test rig used here consists of $1 / 3$ rdhp compressor with hermetic shield. It consists of a compressor that is connected to a condenser, capillary tube, and an evaporator by appropriate pipelines. In the refrigeration line from the condenser to the evaporator, an appropriate filter and a gauge glass are filled in to visually absorb the liquid refrigerant. A thermometer is installed in the evaporator tank for calculating the temperature of the water. The energy input to the compressor is measured with water. To research the refrigeration process, appropriate pressure gauges are installed for the Inlet and exit of compressor and evaporator. The inlet power supply is also monitored by a Voltmeter and ammeter. If an additional Freon is needed, a provision is provided for changing the refrigerant pipelines within the test rig. The vapor-state refrigerant that comes out of the evaporator compressed in a compressor is sent to the condenser condensed in to liquid and then throttled. The temperature of the refrigerant drops due to throttling, and then it passes by the evaporator which takes up heat from the object to be cooled. The refrigerant then returns to the compressor where it completes its cycle. 


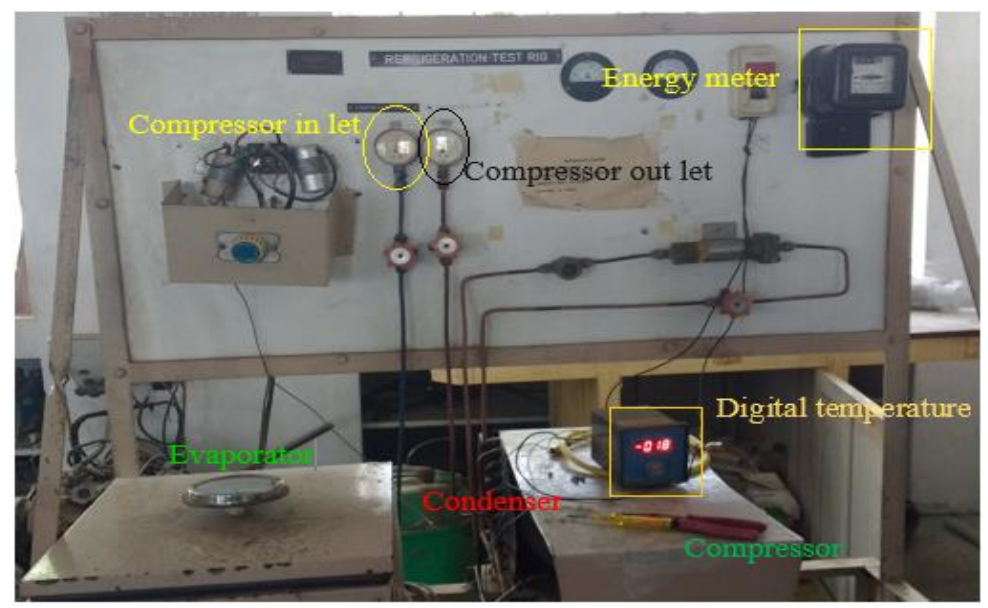

Figure 1: Basic Refrigeration Test Rig

\subsection{Compressor}

A compressor is the most critical and often the most expensive part of any VCR system (typically 30-40\% of total cost). The role of a compressor in a VCR system is continuously remove the evaporator refrigerant vapor in order to maintain low pressure and low temperature in evaporator where the refrigerant will boil heat from cooling region. The compressor will then boost the refrigerant pressure to a point at which it can condense by refusing heat from the condenser to the cooling medium. For this experiment, hermetically sealed compressor is used, to avoid refrigerant leakage the motor and compressor are housed in the same housing. The housing has welded inlet, drain, and power inlet socket connections for refrigerant. As a result of this, refrigerant leakage from the compressor is practically not necessary.

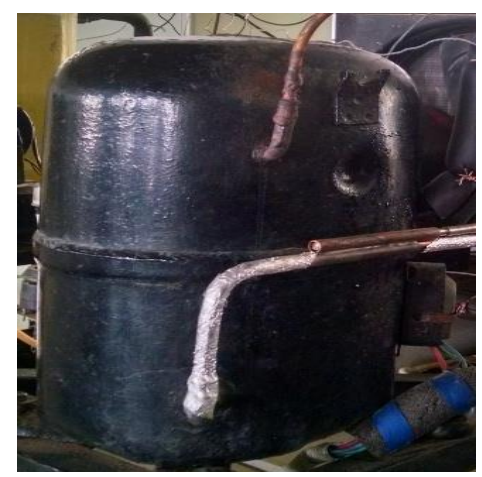

Figure 2: Hermetic Compressor

\subsection{Modified Refrigeration Test Rig}

Additionally an Ejector, nozzle, and separator are mounted in an ejector expansion vapor compression refrigeration process. An ejector is an expansion device to reduce the throttling losses of the expansion device, in addition to the throttling valves. The ejector is installed at the condenser outlet, and at relatively high pressure, the motive fluid (liquid from the condenser) enters the nozzle. Reducing the liquid pressure in the nozzle provides the potential power for conversion to the liquid's kinetic energy. Driving flow enters out of the evaporator vapor. The two- phases are combined in a mixing chamber and then left in the ejector's diffuser portion after the pressure recovery. Using a small pressure-drop expansion system, the liquid portion is guided to The evaporator while portioning the vapor reaches the suction of the compressor. The correct installation of the ejector raises the refrigeration system's COP by increasing the compression suction pressure in the evaporator to a degree higher than that and thereby raising the compressor and engine load. 


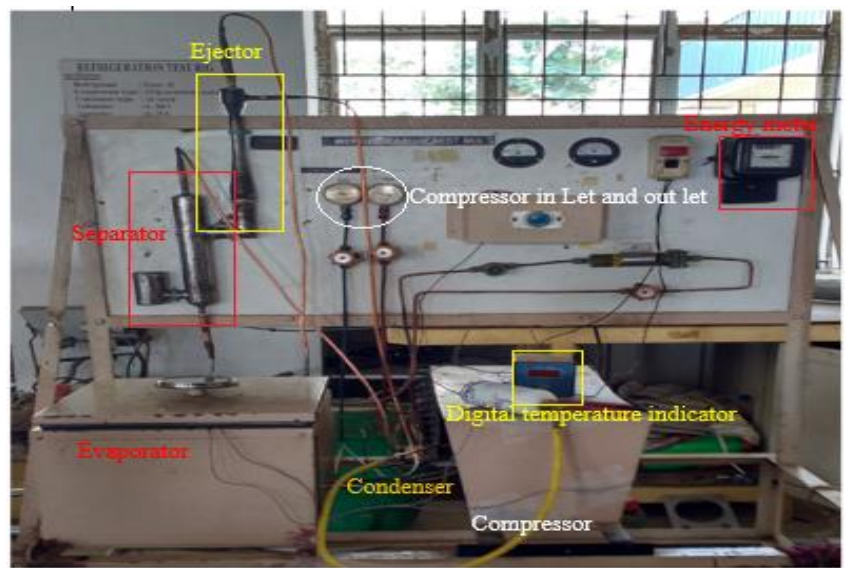

Figure 3: A modified Refrigeration test rig

\subsection{Two-phase Ejector as a Refrigerant Expander}

The vapor compression cycle COP can be strengthened by incorporating some kind of work-producing tool, transforming the isenthalpic mechanism into an essentially isotropic one. The move would offer two benefits are Reducing the refrigerant enthalpy entering the vapour and providing work to assist the power compressor. An ejector is suggested to be used as an expander to the refrigerant. The high pressure liquid which leaves the condenser is used as the motivating fluid of the ejector which partially compresses the saturated vapor leaving the evaporator. At a frequency between the evaporator level and the compressor discharge pressure, A two phase flow leaves behind the ejector. The liquid component of this discharge is returned to the evaporator whereas the portion of the Vapor is fed into the suction compressor. Essentially, the result is a two-stage cooling unit with work, otherwise lost in the high-stage expansion Cycle providing low-stage input for the work. The low stage throttling process transmits a small difference in pressure and therefore causes little loss.
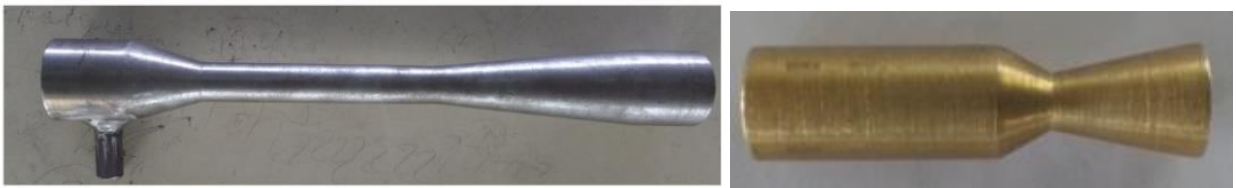

Figure 4: Two-phase ejector Figure 5. Convergent Divergent Nozzle

\subsection{Two-Phase Separator (Vapour-Liquid Separator)}

A separator of vapor-liquid is a tube into which a mixture of liquid and vapor are fed and in which the liquid is separated by gravity, falls down to the vessel's bottom and is extracted. The vapor flows up on a design pace that minimizes the entrenchment of all those droplets of liquids it reaches the top of the vessel as it is in the vapour.

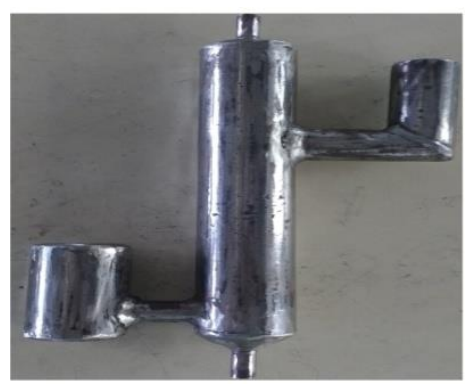

Figure 6: Two-Phase Separator

\section{EXPERIMENTAL PROCEDURE}


The Evaporator tank is filled with a specified quantity and the refrigerant R12 is then poured in. Initial reading of the energy meter and water temperature in the evaporator must be noted down after hitting a steady-state. Say 30 min down the energy meter reading and water temperature after a known period. Until the water temperature is recorded, manually stir the water to ensure temperature in the water tank is uniform. After that test rig the ejector system is adjusted and COP with and without the ejector system is measured for the R134a refrigerant.

\section{RESULTS AND DISCUSSIONS}

Several tests on the same test rig were performed, maintaining similar atmospheric conditions throughout the experiment. The experimentation began with the installation of all the equipment and troubleshooting bugs that are common in any event. The first step is to adjust the refrigerant in the compressor; the gas welding process was installed later with the ejector and separator. We used two refrigerants: R12 and R134a. For better mixing of refrigerant a convergent and divergent nozzle used in the ejector. The following parameters were considered to calculate the COP of the refrigerator: Initial temperature of water (Ti), Final temperature of water (Tf), Initial energy meter reading (Ei), 4.Final energy meter reading (Ef), Mass of water taken (mf), Calorific value of water(Cp), Temperature difference( $\Delta \mathrm{T})$, Energy Consumption of compressor for one hour (kW-hr).

Table 1: Comparison of COP experimentally

\begin{tabular}{|l|c|c|}
\hline & R12 & R134 a \\
\hline COP without ejector & 1.978 & 2.368 \\
\hline COP with ejector & 2.427 & 2.691 \\
\hline
\end{tabular}

Table 2: Comparison of Energy consumption experimentally

\begin{tabular}{|l|c|c|}
\hline & R12 & R134a \\
\hline Without ejector & 972 & 900 \\
\hline With ejector & 792 & 792 \\
\hline
\end{tabular}

Thus there is an increase in the performance of refrigerator by reducing the energy input of the compressor.

\section{CONCLUSIONS}

After performing and validating several experiments, the following results were noted:

- The given refrigeration test rig is performed with two refrigerants R12 and R134a, and the readings were taken with and without ejector.

- $\quad$ The test rig has given higher COP with R12 than R134a.

- For R12 with an ejector, there is a COP improvement of $22.7 \%$

- $\quad$ For R134a with an ejector, COP has increased by $13.59 \%$.

- The Ejector refrigeration system has given better COP as well as reduced the Compressor energy consumption.

- The compressor which is initially held for the test rig (hermetically sealed compressor) works well with both R12 than R134a.

- With working fluid as R134a, the compressor has taken more work input than R12. 
- , higher reliability; ability to handle two-phase flow without any damage to the system, low cost compared to conventional systems.

\section{REFERENCES}

1. Huashan Li, Fei Cao, Xianbiao Bu, Lingbao Wang and Xianlong Wang. Performance characteristics of R1234yf ejectorexpansion refrigeration Cycle. Applied Energy 121 (2014) 96-103

2. Fang Liu, Eckhard A. Groll, Jianxing Ren. Comprehensive experimental performance analyses of an ejector expansion transcritical CO2 system. Applied Thermal Engineering 98 (2016) 1061-1069

3. Lixing Zheng, Jianqiang Deng, Yang He, Peixue Jiang. Dynamic model of a transcritical CO2 ejector expansion refrigeration system. International Journal Of Refrigeration 60 (2015) 247-260

4. Gourav Patel, Dr. Sharad Chaudhary. Perfomance Comparison of Ejector Expansion refrigeration Cycle with Throttled Expansion Cycle Using R-170 as Refrigerant. International Journal of Scientific and Research Publications, Volume 4, Issue 7, July 2014

5. Kapil Dev Choudhary, M.S. Dasgupta, Shyam sunder. Energetic and Exergetic Investigation of a N2O Ejector Expansion Transcritical Refrigeration Cycle Energy Procedia 109 ( 2017 ) 122 - 129

6. Krzysztof Banasiak, Armin Hafner, Trond Andresen. Experimental and numerical investigation of the influence of the two-phase ejector geometry on the performance of the R744 heat pump. International Journal of Refrigeration 35 (2012) 1617-1625

7. Stefan Elbel, Pega Hrnjak. Experimental validation of a prototype ejector designed to reduce throttling losses encountered in transcritical R744 system operation. International journal of Refrigeration 31 (2008) 411-422

8. Christian Lucas, Juergen Koehler. Experimental investigation of the COP improvement of a refrigeration cycle by use of an ejector. International journal of Refrigeration 35 (2012) 1595-1603

9. Yanshuang Huai, Xianmin Guo, Yaoguang Shi. Experimental Study on Performance of Double-Throttling Device Transcritical CO2 Ejector Refrigeration System. Energy Procedia 105 ( 2017 ) 5106 - 5113

10. Li Zhao a, Xingyang Yang, Shuai Deng, Hailong Li, Zhixin Yu. Performance analysis of the ejector-expansion refrigeration cycle using zeotropic. International journal of Refrigeration 57 (2015) 197-2

11. Somchai Wongwises, Somjin Disawas. Performance of the two-phase ejector expansion refrigeration cycle. International Journal of Heat and Mass Transfer 48 (2005) 4282-4286

12. Rounak Sahni. Ejector Expansion Refrigeration Systems. International Journal Of Engineering And Science Vol.5, Issue 2 (February 2015), PP 25-29

13. Mark J. BERGANDER. Refrigeration Cycle With Two-Phase Condensing Ejector International. Refrigeration and Air Conditioning Conference at Purdue (2006). July 17-20, Paper 748.

14. Mortaza Yari. Performance analysis and optimization of a new two-stage ejector-expansiontranscritical CO2 refrigeration cycle. International Journal of Thermal Sciences 48 (2009) 1997-2005

15. Sudhanshu Paul, Raj Prabhat, Kevin Varkey Koshy, Abhishek Gaikwad \& Jude James, "Fabrication and Testing of Thermoelectric Refrigeration System”, International Journal of Mechanical Engineering (IJME), Vol. 5, Issue 4, pp. 85-92

16. Abdel Amir. M. Fenjan \& Inas Salim Mahdi, "Synthesis and Characterization of Some Novel 1,3-Thiazine Derivatives Derived from Coumarin", BEST: International Journal of Humanities, Arts, Medicine and Sciences (BEST: IJHAMS), Vol. 3, Issue 9, pp. $93-100$ 
17. Abdul Samad Mangsi, Muhammad Khaskheli, Aijaz Hussain Soomro \& Muhammad Ghiasuddin Shah, "Antibiotic Residues Detection in Raw Beef Meat Sold for Human Consumption in Sindh, Pakistan”, IMPACT: International Journal of Research in Applied, Natural and Social Sciences (IMPACT: IJRANSS), Vol. 2, Issue 7, pp. 15-20

18. Talal Abu Mansour,Salameh Sawalha\& Nesreen Salem, “A Mathematical Model for Solar Assisted Automobile A/C Based on Absorption Refrigeration System”, International Journal of Mechanical Engineering (IJME), Vol. 2, Issue 4, pp. 75-86 